\title{
SIKAP PETANI TERHADAP KEGAGALAN PRODUKSI USAHA TANI PADI SAWAH DI DESA MAGEPANDA, KECAMATAN MAGEPANDA KABUPATEN SIKKA
}

\author{
Sarlina Noni \\ Universitas Nusa Nipa, Jln. Kesehatan No. 03 Maumere, Flores, NTT 86111 Tel. (0380) 22388, \\ sarlinanoni72@gmail.com
}

Diterima 20 Januari 2019, disetuji 22 Februari 2019, diterbitkan 30 April 2019

Pengutipan: Noni, S.(2019). Sikap Petani Terhadap Kegagalan Produksi Usaha Tani Padi Sawah di Desa Magepanda, Kecamatan Magepanda, Kabupaten Sikka. Gema Wiralodra, Vol 10, No 1, Hal 53-61, April 2019

\begin{abstract}
ABSTRAK
Upaya peningkatan produksi pangan senantiasa mendapat perhatian karena kebutuhan akan beras terus meningkat. Tujuan penelitian ini mengetahui pengaruh antara faktor pembentuk sikap dengan sikap petani terhadap kegagalan produksi usahatani padi sawah di Desa Magepanda Kecamatan Magepanda Kabupaten Sikka. Jenis penelitian yang digunakan dalam penelitian ini adalah jenis penelitian deskriptif kuantitatif dan korelasi. Kuantitatif yaitu data yang diukur dalam suatu numeric (angka) dengan tujuan untuk menguji hipotesis yang telah ditetapkan. Data yang digunakan dalam penelitian ini adalah data primer. Berdasarkan hasil analisis data, maka dapat disimpulkan bahwa sikap petani terhadap kegagalan produksi di kelompok tani Desa Magepanda, dengan menggunakan metode analisis fishbein berdasarkan pada enam atribut diperoleh rata-rata skor sebesar 85,17 yang dikategorikan positif. Artinya sikap petani di kelompok tani desa magepanda menerima kegagalan produksi sebagai motivasi keberlanjutan kegiatan produksinya. Hasil analisisKoefisien Determinasi $\left(\mathrm{R}^{2}\right)$ sebesar 0, 185 yang berarti bahwa kontribusi variabel sikap petani (X) terhadap kegagalan produksi (Y) pada kelompok tanii di Desa Magepanda sebesar $18,5 \%$. sedangkan sisanya sebesar $81,5 \%$ dijelaskan oleh variabel-variabel lain yang tidak diikut sertakan dalam model penelitian ini. Hasil analisa regresi linear sederhana dapat diketahui bahwa variabel sikap petani $(X)$ diperoleh : $-2,613<-2,042$, sehingga Ho ditolak dan Ha diterima artinya sikap petani (X) berpengaruh signifikan terhadap kegagalan produksi (Y).
\end{abstract}

Kata kunci: Petani, produksi, padi.

\begin{abstract}
ABSTRATC
Efforts to increase food production always receive attention because the need for rice continues to increase. The purpose of this study was to determine the effect of factors forming attitudes with the attitude of farmers to the failure of production of lowland rice farming in Magepanda Village, Magepanda Subdistrict, Sikka District. The type of research used in this study is quantitative descriptive research and correlation. Quantitative is data that is measured in a numeric (number) with the aim of testing a predetermined hypothesis. The data used in this study are primary data. Based on the results of data analysis, it can be concluded that the attitude of farmers towards production failure in the farm group of Desa Magepanda, using the fishbein analysis method based on six attributes obtained an average score of 85.17 which is categorized as positive. This means that the attitude of farmers in the Magepanda village farmer group accepts production failure as a motivation for the sustainability of their production activities. The results of the Analysis of Determination Coefficient (R2) are 0, 185 which means that the contribution of the variable farmer attitude $(\mathrm{X})$ to production failure $(\mathrm{Y})$ in the farmer group in Magepanda Village is $18.5 \%$. while the remaining $81.5 \%$ is explained by other variables not included in this research model. The results of simple linear regression analysis can be seen that the farmer attitude variable (X) is obtained: $2,613<-2,042$, so Ho is rejected and Ha is accepted, meaning that the attitude of farmers $(\mathrm{X})$ has a significant effect on production failure $(\mathrm{Y})$.
\end{abstract}

Keywords: Farmers, production, rice 


\section{PENDAHULUAN}

Ketahanan pangan merupakan bagian terpenting dari pemenuhan hak atas pangan sekaligus merupakan salah satu pilar utama hak asasi manusia (Fagi, 2013). Ketahanan pangan juga merupakan bagian sangat penting dari ketahanan nasional. Kelaparan dan kekurangan pangan merupakan bentuk terburuk dari kemiskinan yang dihadapi rakyat, dimana kelaparan itu sendiri merupakan suatu proses sebabakibat dari kemiskinan. Usaha pengembangan ketahanan pangan tidak dapat dipisahkan dari usaha penanggulangan masalah kemiskinan (Krisnamurthi, 2003).

Upaya peningkatan produksi pangan senantiasa mendapat perhatian karena kebutuhan akan beras terus meningkat (Badan Penelitian dan Pengembangan Pertanian, 2015). Upaya ini perlu diikuti dengan upaya peningkatan pendapatan petani agar termotivasi untuk lebih produktif.Pengelolaan tanaman dan sumberdaya terpadu padi sawah merupakan suatu upaya pendekatan untuk meningkatkan dan menstabilkan program produksi padi melalui integrasi pendekatan teknologi sekaligus meningkatkan pendapatan petani.

Kabupaten Sikka termasuk salah satu kabupaten yang sebagian besar penduduknya bermata pencaharian sebagai petani. Beras yang menjadi bahan pangan pokok penduduk Indonesia sangat penting peranannya dan patut menjadi perhatian utama. Berbagai upaya dalam rangka meningkatkan produksi padi harus terus digalakkan mempertimbangkan bahwa beras tetap menjadi sumber makanan pokok bagi sebagian besar penduduk Indonesia. Salah satu sentra produksi padi sawah di Kabupaten Sikka adalah Kecamatan Magepanda.

Varietas padi sawah yang dominan dikembangkan oleh masyarakat tani di Desa Magepanda adalah varietas ciherang. Kecamatan Magepanda merupakan salah satu kecamatan yang memiliki potensi untuk dikembangkan tanaman pangan khususnya padi sawah, karena sebagian besar penduduknya memiliki areal lahan persawahan yang cukup luas, namun produktivitas padi yang dihasilkan masih sangat rendah.Berdasarkan wawancara langsung yang diperoleh dari para petani di Desa Magepanda khususnya kelompok tani salah satunya kelompok tani Jaya Bersama disebutkan bahwa sebagian besar mengalami gagal panen sejak lima tahun terakhir (2012-2017) yang disebabkan oleh banyak faktor diantaranya adalah waktu panen yang kurang tepat, kekeringan, anomali iklim, penggunaan alat yang tidak tepat sasaran dan pengetahuan petani yang masih terbatas tentang penanganan pasca panen, sehingga mengakibatkan tingkat kehilangan hasil tinggi dan berakhir pada kegagalan produksi atau penurunan produksi.Upaya 
peningkatan produksi usahatani padi sawah sudah dilakukan, namun hasil panen masih tetap rendah.

Menghadapi masalah produktivitas yang rendah dalam hal ini jumlah panen yang menurun, maka perlu diperhatikan tentang sikap para petani padi dalam memproduksi usahatani padi sawah. Sikap positif atau negatif seorang petani terhadap pekerjaan berusaha taninya sangat tergantung dari petani yang bersangkutan maupun kondisi lingkungan (Atmaja, 2015). Menurut penelitian yang dilakukan oleh Walgito (2003), sikap yang ada pada diri seseorang dipengaruhi oleh faktor internal, yaitu faktor fisiologis dan psikologis, serta faktor eksternal, yaitu berupa situasi yang dihadapi individu, normanorma, dan berbagai hambatan dan dorongan yang ada dalam masyarakat. Sedangkan penelitian yang dilakukan olek suharyanto dkk (2015) Risiko produksi usahatani padi sawah yang diusahakan pada musim kemarau memiliki risiko produksi yang lebih rendah dibandingkan pada musim hujan. Risiko produksi padi sawah juga lebih tinggi pada lahan bukan milik dibandingkan lahan dengan status milik sendiri.

\section{METODE PENELITIAN}

Jenis penelitian yang digunakan dalam penelitian ini adalah jenis penelitian deskriptif kuantitatif dan korelasi. Kuantitatif yaitu data yang diukur dalam suatu numeric (angka) dengan tujuan untuk menguji hipotesis yang telah ditetapkan. Data yang digunakan dalam penelitian ini adalah data primer. Metode deskriptif adalah untuk mendeskripsikan atau memberi gambaran terhadap objek yang diteliti melalui data sampel atau populasi sebagaimana adanya, tanpa melakukan analisis dan membuat kesimpulan yang berlaku untuk umum, sedangkan korelasi yaitu suatu metode untuk mempelajari sejauhmana variabel -variabel dalam suatu objek berkaitan dengan satu atau lebih variabel dalam objek tersebut atau objek lain, menggunakan perhitungan koefisien korelasi (Sugiyono, 2011).

\section{HASIL DAN PEMBAHASAN}

Analisis Sikap Petani Terhadap Kegagalan Produksi Usahatani Padi Sawah di Desa Magepanda. Sikap petani terhadap kegagalan produksi usahatani padi sawah, diketahui dengan melihat jawaban-jawaban responden (petani) terhadap pernyataan yang dijawab dalam kuisioner. Pernyataan yang digunakan dalam penelitian ini berupa pernyataan positif sebanyak 36 nomor dengan skor setiap jawaban, sangat setuju (5), setuju (4), netral (3), kurang setuju (2) dan tidak setuju (1). Dari hasil seluruh jawaban responden ditabulasi 
berdasarkan masing-masing atribut dengan menggunakan skor belief (kepercayaan) dan evaluation (keyakinan) seperti pada tabel berikut.

Tabel 1. Analisis atribut (skor belief dan evaluation) petani responden terhadap terhadap kegagalan produksi

\begin{tabular}{|c|c|c|c|c|}
\hline \multirow[b]{2}{*}{ No } & \multirow[b]{2}{*}{ Atribut } & \multicolumn{2}{|c|}{ Penilaian Sikap } & \multirow[b]{2}{*}{$\begin{array}{l}\text { Kategori } \\
\text { Sikap }\end{array}$} \\
\hline & & $\begin{array}{c}\text { Rata-Rata } \\
\text { Skor Belief } \\
\text { (bi) }\end{array}$ & $\begin{array}{c}\text { Rata-Rata Skor } \\
\text { Evalution (ei) }\end{array}$ & \\
\hline 1 & Pengalaman pribadi & 4,00 & 4,45 & Positif \\
\hline 2 & Pengaruh orang lain & 3,79 & 3,96 & Positif \\
\hline 3 & Pengaruh kebudayaan & 2,38 & 3,02 & Netral \\
\hline 4 & Media masa & 2,85 & 3,45 & Netral \\
\hline 5 & Lembaga pendidikan & 3,31 & 3,64 & Netral \\
\hline 6 & Faktor emosional & 4,30 & 4,43 & Positif \\
\hline
\end{tabular}

Berdasarkan hasil analisis dan data pada tabel 1. diuraikan bahwa rata-rata belief total skor untuk atribut Pengalaman pribadi sebesar 4,00 hal ini menunjukan petani Desa Magepanda menyatakan percaya dan positif bahwa kegiatan produksi usahatani padi sawah di Desa Magepanda merupakan keberlanjutan dari pengalaman pribadi petani selama melakukan kegiatan usahatani.

Rata-rata belief total skor untuk atribut pengaruh orang lain 3,79 ini menunjukan bahwa petani di Desa Magepanda menanggapi secara positif percaya bahwa peran orang lain terhadap petani untuk kegiatan usahatani padi sawah sangat bergantung pada pendirian petani yang bersangkutan. Rata-rata belief total skor untuk atribut pengaruh kebudayaan 2,38 hal ini menunjukan petani di kelompok tani Desa Magepanda menyatakan percaya dan netral bahwa kegiatan produksi usahatani padi sawah di Desa Magepanda saling mendukung dan tidak bertentangan dengan kebudayaan petani.

Rata-rata evaluationtotal skor untuk atribut emosional4,43 hal ini menunjukan petani di Desa Magepanda menanggapi secara positifdan yakin, bahwa peran emosional bisa saja berpengaruh dan bisa saja tidak berpengaruh terhadap petani dalam menerima hasil yang diperoleh dalam kegiatan produksi usahataninya. Berdasarkan rata-rata skor belief dan evaluation masing-masing atribut maka selanjutnya dapat diketahui sikap petani pada setiap atribut dan skor sikap secara keseluruhan terhadap produksi usaha tani padi sawah di Desa Magepanda seperti pada tabel berikut. 
Tabel 2. Analisis Sikap Petani Terhadap Kegagalan Produksi Usaha Tani Padi Sawah

\begin{tabular}{llll} 
No & Atribut & \multicolumn{2}{l}{$\begin{array}{l}\text { Rata } ~ \\
\text { Petani }\end{array}$} \\
& & 20,22 & Kata Skor Sikap \\
\hline 1 & Pengalaman pribadi & 15,36 & Positif \\
\hline 2 & Pengaruh orang lain & 8,09 & Netral \\
\hline 3 & Pengaruh kebudayaan & 10,32 & Netral \\
\hline 4 & Media Masa & 11,91 & Netral \\
\hline 5 & Lembaga Pendidikan & 19,27 & Positif \\
\hline 6 & Emosional & $\mathbf{8 5 , \mathbf { 1 7 }}$ & Positif \\
\hline & Rata-rata total skor & &
\end{tabular}

(Sumber : Analisis data primer, 2018

Secara keseluruhan rata-rata skor sikap petani di kelompok tani Desa Magepanda terhadap kegagalan produksi usahatani padi berdasarkan enam atribut sebesar 85,17 dengan kategori positif (lampiran). Untuk mengetahui kategori sikap petani di kelompok tani Desa Magepanda terhadap Produksi Usahatani Padi Sawah di Desa Magepanda pada 32 responden disajikan pada tabel berikut.

Tabel 3. Kategori sikap petani terhadap produksi usahatani padi sawah di kelompok tani Desa Magepanda

\begin{tabular}{clcc}
\hline No & Kategori Sikap & Jumlah (Jiwa) & Prosentase (\%) \\
\hline 1 & Positif & 6 & 18,75 \\
\hline 2 & Netral & 26 & 81,25 \\
\hline 3 & Negatif & 0 & 0 \\
\hline & Jumlah & $\mathbf{3 2}$ & $\mathbf{1 0 0}$ \\
\hline
\end{tabular}

(Sumber : Analisis data primer, 2018)

Dari tabel 3. kategori sikap terlihat bahwa responden yang bersikap positif berjumlah 6 orang $(18,75 \%)$, responden yang bersikap netral sebanyak 26 orang $(81,25 \%)$ dan responden yang bersikap negatif sebanyak 0 orang $(0 \%)$, artinya sikap petani secara umum dikategorikan netral. 
Tabel 4. Hubungan kepemilikan lahan dengan sikap petani terhadap kegagalan produksi Usahatani Padi sawah di Desa Magepanda

\begin{tabular}{|c|l|c|c|c|c|}
\hline \multirow{2}{*}{ No } & \multirow{2}{*}{ Sikap Petani } & \multicolumn{4}{|c|}{ Status Kepemilikan Lahan } \\
\cline { 3 - 6 } & & \multicolumn{3}{|c|}{ Pemilik } & \multicolumn{2}{c|}{ Penggarap } \\
\cline { 3 - 6 } & & $\begin{array}{l}\text { Jumlah } \\
\text { (Jiwa) }\end{array}$ & $\begin{array}{l}\text { Prosentase } \\
(\%)\end{array}$ & $\begin{array}{l}\text { Jumlah } \\
\text { (Jiwa) }\end{array}$ & $\begin{array}{l}\text { Prosentase } \\
(\%)\end{array}$ \\
\hline 1 & Positif & 6 & 18,75 & 0 & 0 \\
\hline 2 & Netral & 26 & 81,25 & 0 & 0 \\
\hline 3 & Negatif & 0 & 0 & 0 & 0 \\
\hline \multicolumn{2}{r}{ Jumlah } & $\mathbf{3 2}$ & $\mathbf{1 0 0}$ & $\mathbf{0}$ & $\mathbf{0}$ \\
\hline
\end{tabular}

(Sumber : Analisis data primer, 2018)

Pada tabel 4. menunjukan bahwa jumlah petani di Desa Magepanda yang memiliki status lahan sebagai pemilik berjumlah 6 jiwa (18.75\%), bersikap positif, 26 jiwa $(81,25 \%)$ bersikap netral

\section{Hasil Uji Instrumen Penelitian}

Variabel Sikap Petani terdiri atas 18 item pertanyaan dan variabel Kegagalan Produksi juga terdiri dari 18 item pertanyaan. Hasil uji validitas dengan menggunakan program SPSS, didapatkan hasil analisis uji validitas menunjukkan pada seluruh item pertanyaan untuk variabel Sikap Petanidan variabel Kegagalan Produksi mempunyai nilai koefisien korelasi lebih besar dari 0,3 sehingga dinyatakan valid. Dengan demikian maka pertanyaan - pertanyaan yang diajukan dalam kuisioner penelitian ini dapat digunakan untuk mengukur variabel penelitian. Hasil uji Reliabilitas dengan menggunakan program SPSS, didapatkan hasil data realibel untuk setiap item.

\section{Uji Normalitas}

Hasil analisis uji normalitas untuk melihat normal tidaknya data dengan menggunakan program SPSS. Berdasarkan uji Kolmogorov- Smirnov di dapatkan hasil yang ditunjukkan pada Tabel berikut ini.

Tabel 5. Hasil Pengujian Normalitas

\begin{tabular}{clcc}
\hline No & Variabel & $\begin{array}{c}\text { Asymp. Sig. } \\
\text { (2-tailed) }\end{array}$ & Keterangan \\
\hline 1. & $\begin{array}{l}\text { Kegagalan } \\
\text { Produksi (Y) }\end{array}$ & 0.341 & Data Berdistribusi Normal \\
\hline 2. & $\begin{array}{l}\text { Sikap Petani } \\
(\mathrm{X})\end{array}$ & 0.093 & Data Berdistribusi Normal \\
\hline
\end{tabular}


Dari hasil pengolahan data pada Tabel 7 diketahui bahwa nilai signifikan untuk semua variabel lebih besar dari 0,05 , sehingga dapat disimpulkan data yang diuji berdistribusi normal.

\section{Analisis Regresi Linier Sederhana}

Hasil analisis Regresi Linier Sederhana dengan menggunakan program SPSS, didapatkan hasil yang ditunjukkan pada Tabel berikut ini :

Tabel 6. Analisis Regresi

\begin{tabular}{|c|c|c|c|c|c|}
\hline \multirow[t]{2}{*}{ Model } & \multicolumn{2}{|c|}{$\begin{array}{l}\text { Unstandardized } \\
\text { Coefficients }\end{array}$} & $\begin{array}{l}\text { Standardized } \\
\text { Coefficients }\end{array}$ & $T$ & \multirow[t]{2}{*}{ Sig. } \\
\hline & $B$ & Std. Error & Beta & & \\
\hline (Constant) & 92.282 & 6.721 & & 13.730 & 0.000 \\
\hline Sikap Petani (X) & -0.318 & 0.122 & -0.431 & -2.613 & 0.014 \\
\hline
\end{tabular}

a. Dependent Variable: Kegagalan Produksi (Y)

Berdasarkan Hasil analisis data pada Tabel 8. di atas, selanjutnya ditentukan model persamaan Regresi linier sederhana sebagai berikut : $\hat{Y}=92.282-0.318 X$

Berdasarkan persamaan regresi di atas, maka interpretasi untuk konstanta dan koefisien regresi dapat diuraikan sebagai berikut:

a. Konstanta (bo) : 92.282

Nilai konstan untuk persamaan regresi adalah 92.282dengan parameter positif. Hal ini berarti bahwa tanpa adanya variabel Sikap Petani (X), maka Kegagalan Produksi (Y) sudah sebesar 92.282 .

b. Koefisien Regresi X (b) : - 0.318

Besar nilai koefisien regresi untuk variabel Sikap Petani (X) adalah- 0.318dengan parameter negatif. Koefisien regresi ini dapat dijelaskan bahwa jika terjadi kenaikan pada variabel Sikap Petani (X) sebesar satu satuan, akan mengakibatkan terjadi penurunan pada variabel Kegagalan Produksi (Y) sebesar 0.318satuan.

\section{Pengujian Hipotesis}

Pengujian hipotesis dilakukan uji $\mathrm{t}$ dengan menggunakan program SPSS16. Berdasarkan analisis data pada Tabel 4.18 di atas, langkah-langkah uji hipotesis (uji-t) adalah sebagai berikut: 
1) Hipotesis

$\mathrm{o}: \mathrm{b} 1=0$,

artinya Sikap Petani(X) tidak berpengaruh signifikan terhadap Kegagalan Produksi (Y)

$\mathrm{a}: \mathrm{b} 1 \neq 0, \quad$ artinya Sikap Petani(X) berpengaruh signifikan terhadap Kegagalan Produksi (Y)

2) Menentukan level of significant.

Pada penelitian ini digunakan level of significant $\alpha=0,05$. Dengan level of significant $\alpha$ $=0,05$ diperoleh $\mathrm{t}_{\text {tabel }}$ sebagai berikut:

$$
\begin{aligned}
& \mathrm{t}_{\text {tabel }} \quad=\alpha / 2 ; \mathrm{n}-\mathrm{k} \\
& =0,05 / 2 ; 32-2 \\
& =0,025 ; 30 \\
& =2,042
\end{aligned}
$$

3) Kriteria Pengujian

Ho diterima apabila: $-2,042 \leq \mathrm{t}_{\text {hitung }} \leq 2,042$

Ho ditolak apabila: $\mathrm{t}_{\text {hitung }}>2,042$ atau $\mathrm{t}_{\text {hitung }}<-2,042$

Hasil perhitungan sesuai Tabel 8 diperoleh $\mathrm{t}_{\text {hitung }}$ untuk Variabel Sikap Petani( $\left.\mathrm{X}_{1}\right)$ sebesar 2.613 .

\section{KESIMPULAN}

1) Berdasarkan hasil analisis data, maka dapat disimpulkan bahwa sikap petani terhadap kegagalan produksi di kelompok tani Jaya Bersama Desa Magepanda, dengan menggunakan metode analisis fishbein berdasarkan pada enam atribut diperoleh ratarata skor sebesar 85,17 yang dikategorikan positif. Artinya sikap petani di kelompok tani desa magepanda menerima kegagalan produksi sebagai motivasi keberlanjutan kegiatan produksinya

2) Hasil analisis uji validitas menunjukkan bahwa dari item pernyataan 1 sampai dengan 36 menunjukkan angka diatas 0,3,sehingga data hasil analisa dapat dikatakan valid. Hasil uji reliabilitas Cronbach's Alpha menunjukkan angka diatas 0,6,sehingga data dapat dikatakan reliabel.

3) Hasil analisisKoefisien Determinasi $\left(R^{2}\right)$ sebesar 0, 185 yang berarti bahwa kontribusi variabel sikap petani $(\mathrm{X})$ terhadap kegagalan produksi $(\mathrm{Y})$ pada kelompok tanii di Desa Magepanda sebesar 18,5\%. Sedangkan sisanya sebesar 81,5\% dijelaskan oleh variabel-variabel lain yang tidak diikutsertakan dalam model penelitian ini. 
4) Hasil analisa regresi linear sederhana dapat diketahui bahwa variabel sikap petani $(X)$ diperoleh : -2,613 <- 2,042, sehingga Ho ditolak dan Ha diterimaartinya sikap petani (X) berpengaruh signifikan terhadap kegagalan produksi (Y).

\section{DAFTAR PUSTAKA}

Atmaja, D.M .(2015). Dampak Strategi Petani Dalam Merubah Arah Pemanfaatan Lahan Sawah Terhadap Kenyamanan Hidup di Kota Denpasar, Media Komunikasi Geografi,Vol. 16, No 1, Hal 1-13, Juni 2015.

Badan Penelitian dan Pengembangan Pertanian. (2015). Memperkuat kemampuan swasembada pangan. Jakarta: IAARD Press

Fagi, A.M. (2013). Ketahanan Pangan Indonesia dalam Ancaman. Analisis Kebijakan Pertanian, Vol 11, No 1, Hal 11 -25

Krisnamurti, B. (2003). Penganekaragaman - Pangan: Pengalaman 40 Tahun dan Tantangan Kedepan. Jurnal Ekonomi Rakyat, Vol 2, No. 7, Oktober 2013.

Suharyanto, dkk. (2015). Analisis Risiko Produksi Usahatani Padi Sawah di Provinsi Bali. Balai Pengkajian Teknologi Pertanian (BPTP) Bali.

Sugiyono. (2011). Metodologi Penelitian Kuantitatif Kualitatif. Bandung: Alfabeta.

Walgito, B. (2003). Psikologi Sosial Suatu Pengantar. Yogyakarta: ANDI Press. 